\title{
O ceticismo filosófico de Descartes: destruição de opiniões e tratamento do duvidoso como falso
}

\section{Philosophical skepticism of Descartes: destruction of opinions and treatment of doubtful as false}

\section{EDGARD VINICIUS CACHO ZANETTE ${ }^{22}$}

Resumo: Considerando as Meditações (1641), neste artigo propomos examinar a dúvida metódica a partir de dois problemas fundamentais que se entrecruzam, a saber: uma crítica às opiniões irrefletidas e, ao mesmo tempo, considerar, provisoriamente, o duvidoso como falso. O texto essencial de nossa abordagem é a Primeira Meditação, sobretudo, os parágrafos segundo e décimo.

Palavras-chave: Descartes. Dúvida Metódica. Ceticismo. Metafísica. Filosofia Moderna.

Abstract: Considering the Meditations (1641), in this paper we propose to examine the methodical doubt from two fundamental problems that cross each other, namely: a critique of unreflective opinions and at the same time, consider provisionally doubtful as false. The essential text of our approach is the First Meditation, especially the second and tenth paragraphs.

Keywords: Descartes. Methodical doubt. Skepticism. Metaphysics. Modern philosophy.

\section{Introdução}

As Meditações de Filosofia Primeira (1641) inicia por uma proposta ousada de investigar a base de nosso saber, colocando em

22 Professor Doutor do Departamento de Filosofia da UERR [Universidade Estadual de Roraima] e ex-acadêmico bolsista do PET/Filosofia da UNIOESTE. 
O ceticismo filosófico de Descartes: destruição de opiniões e tratamento do duvidoso como falso

dúvida tudo o que seja incerto ou não fundamentado. Fundamentação da ciência rigorosa contra um passado irrefletido. Emancipar o espírito diante de preconceitos enraizados em nossa natureza e na cultura em que vivemos. Criar uma ciência e desenvolver uma sabedoria capaz de dar conta de aspectos fundamentais de nossa natureza finita e limitada. Enfim, Descartes se lança em combater uma visão de saber que não contemplava satisfatoriamente as descobertas filosóficas e científicas dos séculos XV e XVI. Ser filósofo, neste caso, é filosofar contra certo saber pré-concebido. Para assegurar uma investigação fidedigna diante de tamanhos desafios, cabe, pois, um método ou um processo de destruição das antigas opiniões, chegando mesmo a tratálas como falsas. Considerando que a Metafísica ou Filosofia Primeira aparece como fundante de um novo saber que estabelecesse bases parra toda a ciência, este método de crítica aos prejuízos é o que permite a descoberta de algo certo e indubitável. Neste artigo investigaremos os parágrafos segundo e décimo da Primeira Meditação, com vistas a elucidarmos duas questões fundamentais que se entrecruzam, a saber: 1) liberdade filosófica de efetivar um método que destrua um passado irrefletido e pré-filosófico; 2) elaboração de um artifício metodológico provisório de tratar as coisas duvidosas como se fossem falsas. Tendo em vista os propósitos delineados acima, em nossa investigação examinaremos o parágrafo segundo da Primeira Meditação, em sua relação íntima com a temática do duvidoso como falso exposta no parágrafo décimo.

\section{A dúvida metódica: destruição das opiniões irrefletidas no parágrafo segundo da Primeira Meditação}

Agora, pois, que meu espírito está livre de todos os cuidados, e que consegui um repouso assegurado numa pacífica solidão, 
aplicar-me-ei seriamente e com liberdade em destruir em geral todas as minhas antigas opiniões. (AT IX-1, p. 13; 1979, p. 85 Tradução da versão francesa - grifo nosso).

Essa é uma passagem importante das Meditações, fundamental para uma pormenorizada interpretação de toda a Primeira Meditação. Vejamos o mesmo parágrafo de um modo um pouco diferente:

É, portanto, em boa hora que, hoje, a mente desligada de todas as preocupações, no sossego seguro deste retiro solitário, dedicarme-ei por fim a derrubar séria, livre e genericamente minhas antigas opiniões (AT VII, p. 17-18; 2004, p. 21-22 - Tradução da versão latina - grifo nosso).

Apesar de as duas passagens citadas logo acima serem correspondentes, parece haver algumas peculiaridades entre ambas que merecem ser exploradas. Notamos que no texto em francês a dúvida seria exercida pelo espírito, que, livre de todos os cuidados e por um ato de sua própria liberdade, destruirá todas as suas antigas opiniões. Já a tradução do latim refere-se à "mente desligada de todas as preocupações", por meio da qual, de forma séria, livre e genérica, se derrubará as antigas opiniões. Neste caso, de duas uma: ou espírito e mente são conceitos correlatos ao cartesianismo, ou haveria uma grave diferença entre ambas as edições das Meditações. Como explica Landim e mesmo Descartes em algumas passagens de suas obras ${ }^{23}$, os

${ }^{23}$ Como esclarece Landim, o termo mens "foi traduzido pelo duc de Luynes para o francês por "espírito". No entanto, quando se trata de demonstrar a distinção real da mente com o corpo, o termo usado pela versão francesa das Meditations é "alma" (LANDIM, 1994, p. 41, n.3). De fato, na passagem citada por nós, o termo latino é "mentem", já o texto em francês refere-se a "esprit", conforme a distinção assinalada por Landim. Segundo o texto cartesiano, entre outras passagens que se referem a essas distinções, nas Quintas Respostas (AT VII, p. 356), Descartes explicita o 
O ceticismo filosófico de Descartes: destruição de opiniões e tratamento do duvidoso como falso

conceitos de espírito e mente são equivalentes em toda a obra de Descartes. Não obstante essa pequena diferenciação quanto à questão expositiva, vimos que seja na edição em latim, ou a em francês, ambas ao seu modo marcam a realização de um exercício mental (ou espiritual), metafísico, de filosofar de forma livre e sem pressupor a existência do mundo externo corpóreo como condição de possibilidade de qualquer conhecimento certo e seguro. Por conseguinte, é justamente por este questionamento à antiga concepção de que todo o conhecimento começaria pela experiência (pressuposição de um mundo externo-corpóreo), no sentido aristotélico-escolástico desta expressão, que procederá a superação dos prejuízos com vistas à descoberta de algo certo e indubitável. Mundo externo e conhecimento sensível deixarão de ser, para o cartesianismo, o conhecimento imediato para tornar-se o mais difícil de conhecer segundo a ordem das Meditações. Porém, como sabemos, nem por isso a existência das coisas materiais será menosprezada por Descartes, visto que a prova da existência dos corpos da Sexta Meditação é um dos movimentos finais e fundamentais às Meditações, ao restabelecer pela garantia divina que há coisas externas materiais existentes, com as quais o homem completo e inteiro, a mistura indiscernível entre mente e corpo, está em contínua relação.

\section{A dúvida metódica: proposições extraídas do parágrafo segundo - Tratamento do duvidoso como se fosse falso}

significado da palavra alma e porque as palavras alma e espírito seriam equivalentes ao longo de suas obras. 
1o Proposição: Se faz indispensável ter o espírito "livre de todos os cuidados" em uma adequada solidão / "A mente desligada de todas as preocupações, no sossego seguro deste retiro solitário”.

2o Proposição: Como expressão de um ato da minha própria liberdade, devo estar determinado "em destruir em geral todas as minhas antigas opiniões" / "Dedicar-me-ei por fim a derrubar séria, livre e genericamente minhas antigas opiniões”.

A partir dessas duas proposições Descartes procura estabelecer as bases da situação ideal em que será possível realizar suas meditações, na qual a mente, ou o espírito, livre e solitário, poderá se aplicar, por um ato de sua própria liberdade, em destruir todas as suas antigas opiniões. Essa situação ideal é organizada, em um primeiro momento, deste modo, mas ela irá sendo, passo a passo, modificada conforme as imposições dos argumentos céticos. A situação descrita é a melhor possível dentro do contexto em que o meditador acredita estar. Para ele, todo o seu saber está assentado sobre princípios duvidosos e incertos, e não há meio de superar essa situação senão empregando seu espírito ou sua mente em uma completa inspeção de todas as suas opiniões.

Ora, não será necessário, para alcançar esse desígnio, provar que todas elas são falsas, o que talvez nunca levasse a cabo; mas, uma vez que a razão já me persuade de que não devo menos cuidadosamente impedir-me de dar crédito às coisas que não são inteiramente certas e indubitáveis, do que as que nos parecem manifestamente ser falsas, o menor motivo de dúvida que eu nelas encontrar bastará para me levar a rejeitar todas. (AT IX-1, p. 13-14; 1979, p. 85 - Tradução da versão francesa - grifo nosso ).

Ora, para isso não será necessário mostrar que todas elas são falsas - o que talvez nunca pudesse conseguir -, mas, porque a razão já me persuade de que é preciso coibir o assentimento, de 
O ceticismo filosófico de Descartes: destruição de opiniões e tratamento do duvidoso como falso

modo não menos cuidadoso, tanto às coisas que não são de todo certas e fora de dúvida quanto às que são manifestamente falsas, bastará que encontre, em cada uma, alguma razão de duvidar para que as rejeite todas. (AT VII, p. 18; 2004, p. 23 - Tradução da versão latina - grifo nosso).

Estas duas passagens são muito próximas, havendo uma pequena distinção que gostaríamos de mencionar. Na tradução do francês aparece certa relação entre "impedir-me de dar crédito às coisas", que muitas vezes os intérpretes não a relacionam ao correlato traduzido do latim que seria: "é preciso coibir o assentimento". A questão de Descartes não é somente o juízo que é feito sobre coisas externas; também o é, isso é verdadeiro, mas sobretudo a questão refere-se ao exercício de controle, de coação do próprio assentimento, primeiramente, referente ao âmbito interno da mente para então referir-se ao juízo sobre coisas externas. Tendo em vista a importância dada à coação do assentimento, podemos interpretar esse parágrafo de dois modos distintos, que são mesmo contrários ou antagônicos. A questão é o que significa neste momento coação do assentimento. Esta distinção é fundamental para entendermos a proposta de tratar as coisas duvidosas como se fossem falsas. Neste caso, podemos delimitar a questão por meio de duas interpretações:

Tese 1) Coação do assentimento é a rejeição de qualquer opinião que contenha algum indício de dúvida, de modo que o duvidoso deve ser rechaçado, tal como rejeitamos o que manifestamente é falso, ou seja, a coação do assentimento consiste em rejeitar provisoriamente tanto o que contiver qualquer indício de dúvida assim como fazemos ao que é manifestamente falso. Assim, há um apelo a uma suspensão provisória do assentimento sobre determinada proposição que se mostrou duvidosa; 
Tese 2) Coação do assentimento é rejeição do duvidoso tratando, já e desde então, o duvidoso como totalmente similar ao falso, ou seja, uma proposição com o mínimo indício de dúvida levará imediatamente à compreensão de que a mesma é completamente falsa. Neste caso, dúvida e falsidade seriam equivalentes.

Diante dessa questão e dessas duas possibilidades interpretativas, propomos mostrar que um possível tratamento do falso como duvidoso desde o início das Meditações, tese 2, seria um contrassenso ao texto cartesiano bem como ao sentido mesmo da dúvida cartesiana. Diante desta controvérsia, sigamos discutindo e verificando se a nossa hipótese interpretativa é sustentável ou não ${ }^{24}$.

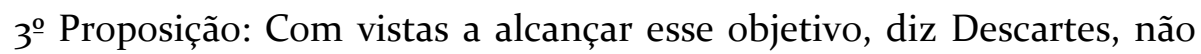
buscarei "provar que todas elas são falsas", mas esforçar-me-ei em não dar crédito "às coisas que não são inteiramente certas e indubitáveis"

$4^{\circ}$ Proposição: Seja qual for o indício de dúvida que eu encontrar em alguma antiga opinião, indistintamente e imediatamente a rejeitarei, pois "o menor motivo de dúvida que eu nelas encontrar bastará para me levar a rejeitar todas"

\footnotetext{
${ }^{24}$ Quanto a esse interessante tema Forlin realiza uma investigação entre as duas interpretações citadas. Considerando essa questão filosófica, a nossa interpretação é próxima da de Forlin em alguns aspectos. Pois, para o intérprete, "a dúvida metódica consiste em duas operações complementares: primeiramente, ela rejeita tudo o que for passível de dúvida; depois, ela rejeita como falso tudo o que for passível de dúvida" (FORLIN, 2006, p. 26). No entanto, entre outras divergências entre a nossa abordagem e a de Forlin quanto à exposição e à compreensão de toda a dúvida metódica, a nossa investigação difere daquela, sobretudo, por que a preocupação fundamental de Forlin é a de mostrar o papel da dúvida metafísica no processo de constituição do cogito, tanto no Discurso do Método quanto nas Meditações, apresentando como contraprova de sua tese os Princípios da Filosofia. Já a nossa proposta não tem o objetivo de investigar a dúvida minuciosamente nestes outros textos de Descartes.
}

Diaphonía, ISSN 2446-7413, v. 1, n. II, 2015 
O ceticismo filosófico de Descartes: destruição de opiniões e tratamento do duvidoso como falso

A destruição de todas as opiniões mal fundadas procederá por análises em blocos que representarão todo um conjunto de opiniões. Essa análise não procurará prová-las todas falsas, pois isso contraria a própria decisão anteriormente estabelecida, de recomeçar tudo desde os fundamentos, mas há um aspecto na frase seguinte a essa que traz um problema interpretativo. Se a razão me persuade a não diferenciar as coisas que não são inteiramente indubitáveis das que manifestamente parecem falsas, ambas serão rejeitadas? Mas em que, porém, consistirá essa rejeição? Tanto o duvidoso quanto o falso serão somente rejeitados, ou o duvidoso será desde então considerado equivalente ao falso? Eis o nosso controverso problema interpretativo.

De um modo ou de outro está claro não haver espaço para a probabilidade ser um critério de verdade, mas o problema interpretativo aqui exposto refere-se ao estatuto dessa rejeição, pois é preciso determiná-la para ter em vista como procedem os argumentos céticos. Com esta última questão se dá uma confusão interpretativa a partir de um dos estudos mais clássicos sobre Descartes que é o de Gueroult. Em um primeiro momento da sua apresentação dos elementos necessários que compõem a dúvida metódica, ele considera o processo da dúvida é constituído por uma tripla necessidade: Em primeiro lugar, a dúvida é prévia, ou seja, ela deve anteceder a descoberta de uma verdade indubitável. Em segundo lugar, é necessário nada excetuar da dúvida, na medida em que a dúvida não é radicalmente impossível, mas, pelo contrário, a dúvida é expressão da própria liberdade humana. Em terceiro lugar, por seu caráter global, há a necessidade de tratar provisoriamente como falsas todas as coisas assim lançadas na dúvida; o que acarreta a necessidade de rejeitá-las inteiramente (Cf. GUEROULT, 1968, p. 33), mas quando ele afirma que há a necessidade de tratar provisoriamente como falsas todas as coisas 
que são lançadas na dúvida, o problema é compreender em que momento isso iniciaria, se já no $1^{\circ}$ grau da dúvida e marcharia ao longo de toda a dúvida cartesiana ou se somente no $3^{\circ}$ grau da dúvida com a aplicação do argumento do Deus Enganador ou do Gênio Maligno.

Gérard Lebrun textualmente afirmando seguir a leitura de Gueroult, nas notas que apresenta à nossa ótima tradução ao português do texto francês das Meditações, afirma que já no $1^{\circ}$ grau da dúvida Descartes trataria o duvidoso como falso. Com efeito, isso é estranho e contraria, segundo nos parece, a própria interpretação de Gueroult, visto que Gueroult considera o tratamento do duvidoso como falso o último estágio da dúvida metódica, completando o argumento psicológico do Gênio Maligno, colocando em questão os erros ou as ilusões que se produzem naturalmente em nosso espírito (o erro dos sentidos, delírio dos loucos, ilusão do sonho). Deriva daí que esse nível da dúvida não segue o modo de operar os argumentos céticos como ocorria no âmbito da dúvida natural, mas estariam alicerçados sobre a hipótese metafísica do engano generalizado. Nessa aparente contradição interpretativa, na nota de Gérard Lebrun sobre o §2 da Primeira Meditação, ele defende que:

[...] a dúvida assim posta em ação: a) distinguir-se-á da dúvida vulgar pelo fato de ser engendrada não por experiência, mas por uma decisão; b) será "hiperbólica", isto é, sistemática e generalizada; c) consistirá, pois, em tratar como falso o que é apenas duvidoso, como sempre enganador o que alguma vez me enganou. (DESCARTES, 1979, p. 86, n. 14).

Podemos comparar os dois parágrafos-chave que apresentam mais nitidamente esse problema interpretativo das traduções do francês e do latim para melhor compreendê-lo: 
O ceticismo filosófico de Descartes: destruição de opiniões e tratamento do duvidoso como falso

(§2) [...] uma vez que a razão já me persuade de que não devo menos cuidadosamente impedir-me de dar crédito às coisas que não são inteiramente certas e indubitáveis, do que às que nos parecem manifestamente ser falsas, o menor motivo que eu nelas encontrar bastará para me levar a rejeitar todas. (AT IX-1, p. 13-14 ; 1979, p. 85 - grifo nosso) / [...] mas, porque a razão já me persuade de que é preciso coibir o assentimento, de modo não menos cuidadoso, tanto às coisas que não são de todo certas e fora de dúvida quanto às que são manifestamente falsas, bastará que encontre, em cada uma, alguma razão de duvidar para que as rejeite todas (AT VII, p. 18; 2004, p. 23 -grifo nosso).

(§10) [...] sou obrigado a confessar que, de todas as opiniões que recebi outrora em minha crença como verdadeiras, não há nenhuma da qual não possa duvidar atualmente, não por alguma inconsideração ou leviandade, mas por razões muito fortes e maduramente consideradas: de sorte que é necessário que interrompa e suspenda doravante meu juízo sobre tais pensamentos, e que não mais lhes dê crédito, como faria com as coisas que me parecem evidentemente falsas [...]. (AT IX-1, p. 17; 1979, p. 88 - grifo nosso) / [...] mas sou finalmente forçado a confessar que nada há de todas as coisas que considerava outrora verdadeiras de que não me seja permitido duvidar, não por não as considerar ou por leviandade, mas por robustas e meditadas razões. Por isso, também a elas não menos que às coisas manifestamente falsas, devo, de agora em diante, negar cuidadosamente o meu assentimento, se quero encontrar algo certo nas ciências (AT VII, p. 22; 2004, p. 31 - grifo nosso).

No §2 Descartes parece relacionar o duvidoso com o falso a partir da rejeição de ambos. Tanto o duvidoso, por menor que seja seu grau de dúvida, quanto o que manifestamente é considerado falso, serão rejeitados imediatamente, por isso cabe seguir coibindo o assentimento, proposição a proposição, que se mostrar duvidosa ou falsa. A situação apresentada pelo §10 parece mais radical, com mais 
firmeza decisória, pois ela resulta, segundo Descartes, de razões mais fortes e maduramente consideradas, interrompendo finalmente os pensamentos, suspendendo o juízo sobre tais pensamentos (texto em francês), ou, por robustas e meditadas razões, negar cuidadosamente o assentimento (texto em latim), não dando crédito às coisas como faria com as que parecem evidentemente, ou manifestamente, falsas.

No §10 as razões consideradas e a impossibilidade de duvidar de outras coisas atualmente indica uma situação diversa sobre 0 tratamento do duvidoso que aquela apresentada anteriormente no §2. Devido a estas razões citadas por nós e tendo em vista o próprio caráter decisório e radical exposto pelo §10, iremos seguir alguns aspectos da interpretação que nos parece mais prudente e correta segundo o que consideramos afirmar o próprio texto de Descartes, em que o tratamento do duvidoso como falso ocorreria somente no $3^{-0}$ grau da dúvida. Esse modo de considerar a questão nos parece mais prudente que o outro na medida em que o julgamento do duvidoso como falso desde o início da dúvida parece contrariar não somente o texto de Descartes, mas também a proposta inicial de somente rejeitar as coisas duvidosas, tal como fazemos com as que manifestamente são falsas, ou seja, há uma coação do assentimento a ser perseguida e não a manifestação imediata de juízos negativos acerca daquilo que se manifesta já no $1^{\circ}$ grau da dúvida como simplesmente duvidoso. Pois, se a dúvida metódica já iniciasse tratando como falsas todas as teses que imediatamente lhe são consideradas como simplesmente duvidosas, essa negação imediata já não seria um bom critério de verdade? Dizendo de outro modo, se antes do processo da dúvida chegar ao seu fim ela já tivesse desde o seu início ao seu fim um critério de julgamento em que o duvidoso é tratado como falso, em que medida seria possível falarmos em uma dúvida metafísica, 
O ceticismo filosófico de Descartes: destruição de opiniões e tratamento do duvidoso como falso

conforme o próprio Descartes defende ser a sua? Por esses e outros problemas, consideraremos que, a partir do $1^{\mathbf{o}}$ grau da dúvida, haveria uma suspensão do juízo, ou suspensão do assentimento, sobre tudo o que manifestamente for duvidoso até que se esgotem todas as razões possíveis de duvidar nesse plano da dúvida. Já o tratamento do duvidoso como falso coroaria o processo da dúvida metódica em transformar-se em negação metódica da dúvida metafísica ${ }^{25}$, como forma de lidar com a possibilidade do engano global ou total.

\section{Referências bibliográficas}

\section{Bibliografia primária}

DESCARTES, R. Euvres. Paris: Vrin, 1996. 11 vol. Publiées par Charles Adam et Paul Tannery, 1973-8.

.Ouvres Philosophiques de Descartes. (O.P.D.), (Org.).

Ferdinand Alquié.3 vol. Vrin: Paris, 1967.

. Discurso do método; Meditações; Objeções e respostas; As paixões da alma; Cartas. 2. ed. São Paulo: Abril Cultural, 1979. (Coleção Os Pensadores).

. Meditações sobre Filosofia Primeira. Tradução: Fausto

Castilho. Ed. Bilíngüe em latim e português - Campinas, SP: Editora da Unicamp, 2004. (Coleção Multilíngües de Filosofia Unicamp - Série A - Cartesiana I).

\footnotetext{
25 Quanto a essa questão, concordamos com a interpretação de Gouhier, principalmente quando afirmamos que "o tratamento do duvidoso como falso coroaria o processo da dúvida metódica em transformar-se em negação metódica da dúvida metafísica”, o que é próximo ao que Gouhier expõe no capítulo I, Seção III, intitulada "Doute et Négation" (GOUHIER, 1999).
} 
. O mundo (ou Tratado da luz) e O homem; apresentação, apêndices, tradução e notas: César Augusto Battisti, Marisa Carneiro de Oliveira Franco Donatelli. Ed. Bilíngüe em francês e português Campinas, SP: Editora da Unicamp, 2009. (Coleção Multilíngües de Filosofia Unicamp - Série A - Cartesiana II).

. Obras filosóficas: objeciones e los princípios de la filosofia. Introdução: Étienne Gilson. Versão espanhola: Manuel de La Revilla. Buenos Aires: Editorial El Ateneu, 1945.

. Princípios da filosofia. Tradução: João Gama. Lisboa:

Edições 70, 1997.

. Regras para a direção do espírito. Tradução: João da Gama.

Lisboa: Edições 70, 1989.

\section{Bibliografia secundária}

ALQUIÉ, Ferdinand. La découverte métaphysique de l'homme chez Descartes. Paris: Presses Universitaires de France, 1950. . Leçons sur Descartes. Paris: La Table Ronde, 2005.

BARON, Jan-Louis Vieillard (Org.). Le problème de l'âme et du dualisme. Paris: Librairie Philosophique J. VRIN, 1992.

BATTISTI, César Augusto. O método de análise em Descartes: da resolução de problemas à constituição do sistema do conhecimento. Cascavel, PR: EDUNIOESTE, 2002 (Série Estudos Filosóficos no 5).

BEYSSADE, Jean Marie. A teoria cartesiana da substância. Equivocidade ou Analogia? Tradução: Lia Levy. In: Analytica. Rio de Janeiro, v. 2, n. 2, p. 11-36, 1997.

BEYSSADE, J-M; MARION, J-L (Org.). DESCARTES. Objecter et Répondre. Paris: Presses Universitaires de France, 1994. 
O ceticismo filosófico de Descartes: destruição de opiniões e tratamento do duvidoso como falso

BIRCHAL, T. S. O cogito como representação e como presença: duas perspectivas da relação de si a si em Descartes. In: Discurso. São Paulo, v. 31, p. 441-461, 2000.

. O eu nos Ensaios de Montaigne. Belo Horizonte, MG:

Editora UFMG, 2007 (Humanitas).

. Dicionário Descartes. Tradução: Helena Martins. Rio de

Janeiro: Jorge Zahar Editor, 1995.

DIÔGENES, Laêrtios. Vidas e doutrinas dos filósofos ilustres. Tradução do grego, introdução e notas: Mário da Gama Kury. 2. ed. Brasília: Ed. Universidade de Brasília, 1977.

DUTRA, Luís Henrique de; SMITH, Plínio Junqueira (Org.). Ceticismo: perspectivas históricas e filosóficas. Florianópolis, SC: NEL UFSC, 2000 (Rumos da Epistemologia; v. 2).

EVA, Luiz. A figura do filósofo: ceticismo e subjetividade em Montaigne. São Paulo: Edições Loyola, 2007.

. O primeiro cético (acerca da coerência do pirronismo). In. O ceticismo e a possibilidade da filosofia. Ijuí, RS: Ed. Unijuí, p. 45-86, 2005 (Coleção Filosofia; 13).

FILHO, Roberto Bolzani. Acadêmicos versus pirronianos: ceticismo antigo e filosofia moderna. In: Discurso. Revista do Departamento de Filosofia da USP. São Paulo: Discurso Editorial, n. 29, p. 57-111, 1998.

. A epokhé cética e seus pressupostos. In. Discurso. Revista do Departamento de Filosofia da USP. São Paulo: Discurso Editorial, n. 27, p. 37-61, 1996.

FORLIN, Enéias. A teoria cartesiana da verdade. São Paulo: Associação Editorial Humanitas; Ijuí: Editora Unijuí/ Fapesp, 2005 (Coleção Filosofia; 14). 
. O argumento cartesiano do sonho. In: Discurso. Revista do Departamento de Filosofia da Usp. São Paulo: E. Discurso Editorial, n. 32, p. 235-248, 2001.

. O papel da dúvida metafísica no processo de constituição do cogito. São Paulo: Associação Editorial Humanitas, 2004. GAUKROGER, Stephen. Descartes: uma biografia intelectual. Tradução: Vera Ribeiro. Rio de Janeiro: Editora UERJ, 1999.

GILSON, E. Études sur le rôle de la pensée médiévale dans la formation du système cartésien. Paris: Vrin, 1930.

GLEIZER, Marcos André. Espinosa e a idéia-quadro cartesiana. In: Analytica. Rio de Janeiro, v. 3, n. 1, p. 75-89, 1998.

GOMBAY, André. Descartes. Tradução: Lia Levy. Porto Alegre, RS: Artmed, 2009.

GOUHIER, Henri. La pensée métaphysique de Descartes. 4. ed. Paris: Librairie Philosophique J. VRIN, 1999.

GRECO, J; SOSA, E (Org.). Compêndio de Epistemologia. Tradução: Alessandra Siedschlag Fernandes e Rogério Bettoni. São Paulo: Ed. Loyola, 2008.

GUENANCIA, P. Descartes. Tradução: Lucy Magalhães. Rio de Janeiro: Jorge Zahar Editor, 1991.

. L'intelligence du sensible: essai sur le dualisme cartésien.

França: Éditions Gallimard, 1998.

GUEROULT, Martial. Descartes selon l'ordre des raisons. Paris: Aubier, 1968, 2 vol.

KOYRÉ, Alexandre. Considerações sobre Descartes. 4. ed. Lisboa:

Editorial Presença, 1992.

LANDESMAN, Charles. Ceticismo. Tradução: Cecília Camargo

Bartalotti. São Paulo: Loyola, 1992. 
O ceticismo filosófico de Descartes: destruição de opiniões e tratamento do duvidoso como falso

LANDIM, Raul Ferreira Filho. A referência ao dêitico "EU” na gênese do sistema cartesiano: A res cogitans ou o homem?. In: Analytica. Rio de Janeiro, v. 1, n. 2, p. 41-67, 1994.

. Evidência e verdade no sistema cartesiano. São Paulo:

Loyola, 1992 (Coleção Filosofia; 23).

. Idealismo ou realismo na filosofia primeira de Descartes.

In: Analytica. Rio de Janeiro, v. 2, n. 2, p. 129-159, 1997.

LEVY, L. Eu sou, eu existo: isto é certo; mas por quanto tempo? In:

Analytica. Rio de Janeiro, v. 2, n. 2, p. 161-185, 1997.

LOPARIC, Zeljko. Descartes heurístico. Campinas, SP: UNICAMP, Instituto de Filosofia e Ciências Humanas, 1997 (Coleção Trajetória; 5).

MAIA NETO, José R. Panorama historiográfico do ceticismo renascentista. In: SKÉPSIS. Ano 1, no 1, p. 83-97, 2007.

MARCONDES, Danilo. Ceticismo, Filosofia cética e linguagem. In: $O$ ceticismo e a possibilidade da filosofia. Ijuí, RS: Ed. Unijuí, p. 135-158, 2005 (Coleção Filosofia; 13).

MARION, J-L. Sur l' ontologie grise de Descartes. 2. ed. PARIS: Vrin, 1991.

MOYAL, J. D. (Ed.). René Descartes critical assessments. London/New York: Routledge, 1991, 4 v.

ONG-VAN-KUNG K. (Org.). Descartes et la question du sujet. Paris:

Presses Universitaires de France, 1999.

POPKIN, Richard H. História do ceticismo de Erasmo a Spinosa.

Tradução: Danilo Marcondes de Souza Filho. Rio de Janeiro: Francisco Alves, 2000.

PORCHAT, Oswaldo P. Rumo ao ceticismo. São Paulo: Editora UNESP, 2007 (Artigos publicados entre 1969 e 2005). 
PRADO JR, Bento (Org.). A filosofia e a visão comum do mundo. São Paulo: Brasiliense, 1981.

ROCHA, Ethel Menezes. Animais, Homens e Sensações Segundo Descartes. In: KRITERION. Belo Horizonte, no 110, p. 350-364, dez./2004.

RODIS-LEWIS, Geneviéve. Descartes: uma biografia. Tradução: Joana d'Ávila Melo. Rio de Janeiro: Record, 1996.

. Descartes e o racionalismo. Tradução: Jorge de Oliveira Baptista. Porto: Rés Editora, 1979.

SEXTO EMPÍRICO. Hipotiposis pirrónicas. Tradução e edição: Rafael Sartorio Maulini. Madrid: Ediciones AKAL, 1996.

. BURY, R. G. (Ed.). The Loeb Classical Library. Cambridge, Massachusetts: Harvard University Press-Londom: William Heinemann, 1976.

SILVA FILHO, Waldomiro José (Org.). O ceticismo e a possibilidade da filosofia. Ijuí, RS: Ed. Unijuí, 2005 (Coleção Filosofia; 13).

SMITH. P. J. Ceticismo filosófico. São Paulo/Curitiba: EPU/Editora da UFPR, 2000.

Passo-a-Passo; 35).

. Ceticismo. Rio de Janeiro: Jorge Zahar, 2004 (Coleção

STROUD, Barry. El escepticismo filosófico y su significación. Tradução:

Letícia García Urriza. México: Fondo de Cultura Econômica, 1991.

VALENTIM, Marco Antônio. "Uma conversação premeditada”: a essência da história na metafísica de Descartes, Rio de Janeiro, 2007. p. 193. Tese (Doutorado em Filosofia) - Programa de Pós-Graduação Filosofia, Instituto de Filosofia e Ciência Sociais, UFRJ.

SOARES, Alexandre Guimarães Tadeu de. O filósofo e o autor. Campinas: Editora Unicamp, 2008. 
O ceticismo filosófico de Descartes: destruição de opiniões e tratamento do duvidoso como falso

ZANETTE, Edgard Vinícius Cacho. Argumentos, ano 4, n. 8, jul./dez. 2012. Resenha de: SALLES, Jordi. “...le persuader aux autres”: le choc avec Hobbes et Gassendi sur le doute. Notes sur la dialogique cartésienne. In: BEYSSADE, J.-M.; MARION, J.-L. (Org.). Descartes: objecter et répondre. Paris: Presses Universitaires de France, 1994. p. 91-109.

. Ceticismo e subjetividade em Descartes. 2011. 154 f. Dissertação (Mestrado em Filosofia) - Programa de Pós-Graduação em Filosofia, Unioeste.

Crítica ao sensível na teoria da alma racional de René

Descartes. 2015. 150 f. Tese (doutorado) - Universidade Estadual de Campinas, Instituto de Filosofia e Ciências Humanas.

WILLIAMS, Bernard. Descartes, el proyecto de la investigación pura. Tradução: Jesús Antonio Coll Mármol. Madrid: Ediciones Cátedra, 1996. 